\title{
Analysis of Speech Humor in Crosstalk From Principles of Cooperation and Relevance Theory
}

\author{
Xia Li \\ Chongqing Normal University, Chongqing, China
}

\begin{abstract}
Cross talk is one of the unique performing arts in China, and most crosstalk gives the audience happy feelings through the delivery of humorous language. This paper interprets the generation of humor in crosstalk through the cooperation principles and the relevance theory, and the generation of the humorous results comes from the contrast between ostensive-inference model and the contrast between maximal relevance and optimal relevance.
\end{abstract}

Index Terms - humorous, cooperative principle, relevance theory

\section{INTRODUCTION}

As people step into the fast-paced life of 996 and with increasing pressure from all circles, people feel more and more anxiety. At present, one way for people to release pressure is to watch a variety of drama programs, such as "Top Funny Comedian", "Smile", etc. Various comedy programs have won the audience applause and smile with different works, their essential feature is that they produce humor. As a common language phenomenon, humor plays an important role in people's life. It can not only relieve their anxiety, tension, but also resolve the embarrassment between people in communication. There are many forms of humor, such as words, facial expressions, body language, especially in discourse. At the same time, as a unique art form of China which inherits a long history, crosstalk is worthy of research and discussion by scholars. This is not only a way to preserve Chinese cultural treasures, but also a way to show Chinese traditional art to the world and carry forward Chinese culture to the world through discussion. Given this, the author will analyze the speech humor in crosstalk from the perspective of cooperation principle and relevance theory. Through the analysis, the author aims to reveal the laughter mechanism in crosstalk for the reference of scholars studying humorous discourse, while further confirming that the principle of cooperation and relevance theory have a strong interpretation of speech humor.

\section{COOPERATIVE PRINCIPLE}

In 1967, the American philosopher Grice, who first proposed the principles of cooperation in his speech "logic and communication", believed that in oral and written communication, people must follow certain rules to achieve the communication effect, that is, the two persons communicate around the same theme and achieve a certain purpose. In this process, both sides should make different efforts to cooperate with each other to make the dialogue go smoothly in the right direction. The principles of cooperation include four maxims, namely maxim of quantity, maxim of quality, maxim of relationship and maxim of manner. Mengjing Liu (2020) said that maxim of quantity requires both sides to provide appropriate amount of information as required without excess information, it includes two more criteria, first, providing the information needed for this communication, second, don't make yourself say more than you ask for, maxim of quality requires that what the communicators say must be true, accurate and supported by certain evidence, that is, first, don't say the words without basis. Second, don't say anything untrue, the maxim of relationship requires that what the two sides says should relate to the subject discussed, maxim of manner requires what the both sides says must be organized, easy to understand, and to avoid ambiguous. However, in everyday life, sometimes somebody may not follow the principles of cooperation in conversation, and the actual situation is that people often violate certain maxims to achieve some purpose. When the listener realizes that the other side has not adhered to the principles, he attempts to identify the other side for the violation and thus infer the implied meaning of the conversation.

\section{RELEVANCE THEORY}

Sperber \& Wilson (2001) said in "Relevance: Communication and Cognition", that relevance theory belongs to the field of cognitive linguistics, mainly studying the discourse in speech communication. In 1995, Sperber \& Wilson proposed two major principles of relevance theory----cognitive and communicative principles. Cognition is designed to maximize the communicative conversation. Their proposed view of communication suggests that communication is a process of explicit---reasoning. Shiyan Zhang (2021) said that the speaker express information, and the listener uses reasoning to understand the meaning of the words expressed by the speaker. The success of communication depends on maintaining the best relevance. The degree of relevance of discourse said by the communication depends on the context 
effect and reasoning effort. Zheshi Mao (2005) said that contextual effect refers to the effect produced by the new information in communication under certain conditions. The greater the effect, the stronger the correlation. The generation of context effect is related to new information and current context assumptions. Jinbang Du \&Weihe Zhong (2013) said that there are three relationships between new information and current context assumptions, firstly, new information strengthens the current context assumptions and makes it more credible, secondly, new information contradicts or conflicts with the current context hypothesis and replaces it, provided that the new information is stronger than the current context hypothesis, thirdly, the new information combines with the current contextual hypothesis to obtain the updated contextual hypothesis . Fei Wang (2017) said that the reasoning effort is that the listener deals with what the speaker says by contextual assumptions and deductive reasoning to derive contextual implications.

\section{Analysis of LANGuage Humour from the View of COOPERATION PRINCIPLES}

Ning Wang (2013) said that Grice noted in his "Logic and Dialogue" that only both sides adhere to cooperation principles in communication and the two were able to have a smooth dialogue. If people intentionally or unintentionally violate one or more principles, it can easily lead to disagreement, conflict, and sometimes humor. The generation of humor is closely related to violations of the principles of cooperation. While this violation does not appear literal uncooperative in most cases, it reflects a deep collaboration. The speakers use this way to express their implied meaning, and humor appears.

\section{A. Humour Caused by Violating of Maxim of Quantity}

Mengjing Liu (2020) said that the maxim of quantity requires both sides in the conversation provide appropriate information, no more or no less. By violating of the maxim of quantity, the two sides provide too much or too little information, too much information will make the listener aware of the humor that the other side wants convey, too little information will make the other side feel ambiguous, resulting in humorous. The author will give two examples to analyze the humor that violates the maxim of quantity below.

A: As long as the weekend, I, my daughter- in-law, My dad and mom, My parents- in -law, a few of us, get up at 3: 30 a. $\mathrm{m}$.

B: Why so early?

A: All of them were responsible for preparing what to use for a day in class.

B: Musical Instruments, books or something else?

A: Yes, Like football, basketball, table tennis, soldier ball, Chinese brush, painting brush, crayon, oboe violin, shelf drum, electric guitar, bass effector, piano conductor and trumpet.

B: OK, don't say more.

A: Pi pa, three-strings and South Xiao.

B: OK, Don't say more, Stop describing it again.

- Selected from "Such a Parent"

In this example, B asked A whether what they had prepared for his child was a musical instrument, books and so on. According to the maxim of quantity, A should answer yes or not, but he continued to list what he had prepared and made the audience laugh.

A: I ask you a little question.

B: You said.

A: Cross talk actors have four subjects which are "say, learn, tease, sing", did you know what are they?

B: Er.....

A: Silly.

B: So do you know what are they?

A: Say, learn, tease, sing ah!

B: Didn't you ask something like this?

A: The answer to the question is just the question itself ah!

B: Ah, I don't know who is wrong between us.

Selected from "The Legend of the White Snake"

In this dialogue, A asked B what were the four subjects "say, learn, tease, sing" that crosstalk actors learned. B failed to give the answer. A said the correct answer was "say, learn, tease, sing". The answer given by A was actually the question itself, so that B failed to answer. According to the principle of cooperation, A obviously violates the quality principle, makes B feel confused, thus makes the audience laugh, produce humor.

\section{B. Humour Caused by Violating Maxim of Quality}

Feng Xie \& Shuyun Zheng (2007) said that violation of quality principles means that the speaker fails to tell the truth or provides information which is short of sufficient evidence. Maxim of quality requires participants to ensure in the dialogue that what they say is real. In a collaborative dialogue, one should avoid lying, exaggerating or boasting and thus follow cooperative principles. However, in many crosstalk, the two sides of the dialogue create humor by violating quality principles. The following are cases in violation of quality principles. 
A: Who do you want to see when you come here? As the name suggests, the steel wire festival.

B: Steel wire festival.

A: Everyone came to see the steel wire.

B: Yes. Wait for a minute.

A: This is the communication between friends.

B: You don't say anything, we come here to see the steel wire in steel wire festival?

A: Of course.

B: So what about the Strawberry Music Festival?

A: See the strawberries.

Selected from "Three Flower Lane"

In the case of A and B, the performance is held in the wire festival, they say the reason that audience come here is to see the wire, but in fact, the wire festival is just a name, the purpose of the audience is to come to listen to crosstalk, so they violated the first criterion of the maxim of quality-----what they said was not true, thus causing humor, making the audience laugh.

A: All of the audience, thank you for getting here so close, standing so straight to listen to me. Today what to say is the character that the helm of the world Jinnan Chen, there is an old-saying that do not see Jinnan Chen in life, no one can call him a hero. He was eight feet tall and his waist is eight feet, too.

B: Wow! Isn't that all square?

A: Four sides mean nothing, like the function of rice is to raise a hundred kinds of people. I will tell you that his martial skills, even nine days and ten Bodhisattva shook his head for fear of thunder palm. A palm was hit, within a hundred miles around, regardless of livestock, shrimp and crabs, fleas, all turned into flying ash ah!

- Selected from "The Deer And the Cauldron"

In this dialogue, A said clearly against facts to highlight the excellent skills of the characters he elaborated, such as A said that nine days and ten Bodhisattva shook his head for fear of thunder palm"! A palm hit, within a hundred miles around, regardless of livestock, shrimp and crabs, fleas, all turned into flying ash ah, it obviously violated the quality principles in the principles of cooperation, making the audience laugh.

\section{Humor Caused by Violating of Maxim of Relationship}

A: It's an old elevator. A big iron fence door is strict and we can see inside from outside and see outside from inside, it is next to a big iron weight, when iron weight goes up, the elevator comes down, as soon as the elevator goes up, the iron weight down, then I was closed here.

$\mathrm{B}$ : What year is the elevator?

A: I don't know the year, maybe the generation of my great grandmother called it my great uncle. Selected from "Elevator Adventure"

In the above example, A wants an answer about the year when the elevator was used: "What year is the elevator?"However, instead of answering his questions directly, B answered some words that seem to be unrelated to A's questions. He replied: "My great grandmother called it my great uncle."Although he did not give a direct answer, it is also seen from his answer that the elevator was old. This answer made the conversation very interesting.

A: In fact, many audience especially like you.

A: (You) have helped me a lot.

B: I dare not say it.

A: If A has such a little achievement, (referring to B)it is so completely effective at myself.

B: If you introduce me, could you please not to describe me using your hands?

A: I am not finished.

B: You say it.

A: Single silk is not a line, lonely wood is not a forest. Iron is an iron nails.

B: It's true.

A: Can you be success without the help of him (referring to B)?

B: Dare not say.

A: Take this opportunity to thank my wife well.

B: I haven't been here.

Selected from "the Discussion of Festivals"

This example is a classic crosstalk in China. The joke that makes the audience laugh is against the principle of relationship. A intended to give thanks to B for his help along the way. Because it is a crosstalk performance, when every topic turns to B, he offered his gratitude to his wife and avoided his original will. There is nothing to do with the original intention of the passage, thus creating a sense of humor that made the audience interesting.

\section{Humor Caused by Violating of Maxim of Manner}

From above, we know that maxim of quantity, quality, and relationship tell people what to say, but maxim of manner tells us how to say. The maxim of manner requires the speaker to avoid obscurity, ambiguity, and should be clearly and orderly. In crosstalk, actors sometimes deliberately speak vague or back-guided words to produce humor. See the 
following example:

A: In fact, my cold is very strange, and my cold comes once a month.

B: Your cold comes once a month?

A: Well.

B: Especially accurate, I catch a cold every month.

A: Once a month he didn't catch a cold, which frightened him a lot.

B: Yes.

- Selected from "Language Art"

In this example, A and B took the cold as the main line, and understood B's cold as an example leave for women returning every month in an ambiguous manner. B replied that "once a month he didn't catch a cold, which frightened him a lot". This sentence made the audience deepen their speculation, thus stimulating funny points and producing humor.

A: "Jin Fei is coming, I tell you, Jin Fei, now the hairdressing salon can not go, do you know? I went there just now, I said that have a perm, you guess what? That person opens her mouth with me for two thousand. "Why so expensive" I said.

B: "sister-in-law, you are wrong, two thousand dollars are just nothing, you grow so beautiful, use two thousand dollars to have a perm, it's worthy, do you know? Just my daughter-in-law, your brother and sister do their hair two days ago which spent 20,000, do you know?"

A: So expensive? Where is it make?

B: At home, take boiling water.

- Selected from "Speak Smoothly"

In this clip, A and B are discussing the price of having a perm. By ironing the multi-layer meaning of the word, making the audience understand become scalded by boiling water, resulting in the cost of 20,000 yuan. Through this ambiguous way, A violates the principle of methods, thus causing humor.

\section{Analysis of LAnguage Humor From the View of ReleVAnce TheOry}

Xue Liang (2012) said that the understanding of humorous discourse is different from the understanding of everyday discourse. First, the listener habitually makes inferences and assumptions under psychology, to obtain the maximum correlation with minimal effort. When the listener realizes that his reasoning and presumption are inconsistent with the intent of the speaker, his original reasoning is fruitless. In order to gain the best relevance, the listener must consider the speaker's discourse again. And the generation of humor lies in the contrast between the maximum correlation and the best correlation. To understand humorous words, it cannot be limited by maximum relevance and stops paying as little effort as possible. Instead, a more effective effort is needed in order to achieve humor. The creation of humor takes advantage of the instinct of people to look for maximum relevance, cleverly setting obstacles, and induce one to consider the perspective of maximum relevance firstly. When people find that maximum relevance does not solve the problem, they turn to best relevance for help and generate humor.

\section{A. Humor Caused by the Contrast of Ostensive-inference Model}

For both parties, the ostensive process is that the speaker expresses the intention of information, the inference is the process when the listener realizes the communication intention. The obedient understands its internal meaning and has communicative intent by inferring the message conveyed by the speaker.

A: How is your father?

$\mathrm{B}$ : My father is gone.

A: When is he gone?

B: A moment ago.

A: Go to the toilet. I come to call him, a person just go.

B: Go where, not gone, he has passed away.

A: Go to the free market, do sales, sell nuts.

B: Who said?

A: Sell a fool melon seeds, that is a fool.

B: Passed away, he has died.

Selected from "The White Council"

In the selected example, B replied "my father is gone" and wanted to euphemistically say that his father died, and A did not reason about the meaning he meant to express, but only understood the literal meaning, so he continued to ask where his father went. The generation of humor here lies in the obedient failure to make appropriate reasoning about the speaker's express information, only focusing on the literal meaning and forming a huge contrast.

A: You drunk and then to drive. Didn't you see how much traffic was going on on the road?

B: I saw it.

A: Dare to open it even?

B: I did not see the police. 
-Selected from "Drinking Without Driving"

In the conversation, A asked B "that you drink and drive, the express purpose is to hope that B can answer to drink without driving, everyone should obey the traffic rules, but B answered "I didn't see the police", the reasoning of B is different from the expected result, which conflicts with the standard answer established by the audience, making the audience reestablish the context and produce humor.

\section{B. Humor Caused by the Contrast between Maximal Relevance and Optimal Relevance}

Liya Song \& Xiaomin Yao (2019) said maximal relevance and optimal Relevance are the two basic concept of relevance theory, maximal relevance is that the listener pays the minimum effort to obtain the maximum contextual effect, and optimal relevance is that the speaker pays enough efforts to obtain the best contextual cognitive effect.

A: But say again, only in school is not good enough, did you sign up for your son' training class?

B: Training class, of course.

A: Say something to me.

B: Chinese, English, mathematics, all of those.

A: Over? My son has already learned it from kindergarten.

B: I also signed up to my son for that talent class.

A: What talent?

B: Painting.

A: You let everyone hear about it, Now painting, calligraphy and piano dance, which child does not learn, is this still called talent, this is a required course

B: What class did you sign up for your son?

A: That is called talent.

B: What talent?

A: Climbing flag poles, play flying forks, hit slingshots, pinch dough, swallow iron balls and chew light bulbs.

B: Your son is a street performer? Besides, it is not a talent, it is a stunt, my god, chew the light bulb.

Selected from "Such a Parent"

In the example, A and B make a conservation about talent class, Wang Kowloon asked "What talent?" A answered climbing the flagpole, playing flying fork, slingshot, pinching dough, swallowing iron balls, chewing light bulbs. B in asking talent, according to the cognitive context of the text and talent definition of life, people will guess piano, chess, painting and calligraphy talent, but A answer talent and listener and the audience's reasoning, so that the audience overturn the previous judgment, draw a new conclusion, form the best association, thus produce the biggest correlation and the best correlation contrast, cause humor.

A: B, I say that this house will be yours, I have evidence, I have a lot have evidence, how well did you talk for so many years

B: A, You are not only good crosstalk, your photography is good, you have held the film festival

A: You have seen?

B: Of course

A: OK, come and sit

B: Of course, you can listen to the name of the festival, "Cattle Watch at Home", it just like judge people by wealth and power ,your Chinese zodiac sign is cattle, my Chinese zodiac sign is a chicken, I hold a film festival called chicken see its feet, right?

At the beginning of this conversation, the context conveyed to the audience is that both people praise each other and think the other party is better, the house should belong to the other. In this cognitive context, B should continue to praise it when he talked about A's show, but the fact is that B began to satirize the name A gave the show was funny. The crosstalk creates humor through the contrast from the beginning to the end.

\section{CONCLUSION}

Daren Tan (1997, p.14) once said: "Language is only used as a tool to cause laughter, humor is the plot recorded by the language, and the language itself is not laughable. But if one returns to the humor of language creation, one can find that it created by the funny person "reversed", "left and right, and created by multiple linguistic means, language is no longer purely a tool of expression, but a source of laughter."As a unique art form in China, crosstalk has brought people a lot of laughter, what this paper discussed is the laughing mechanism of all levels of language. It examines how cross talk people use language elements to create language humor and achieve the purpose of communication. Through analysis, it is found that speech humor in crosstalk is a worthy topic worth research, crosstalk is the language art, and the formation of funny purpose is closely related to language skills. This paper collects statistical typical humorous fragments of counterpart crosstalk based on facts. The double crosstalk between A and B is analyzed from the perspective of cooperation principles and relevance theory respectively, and the reasons for the humorous jokes are drawn. From the perspective of cooperation principle, the author analyzes the crosstalk from the principle of quantity, quality, relationship and manner. Each excerpt crosstalk violates the principle of quantity, principle of quality, principle of relationship and principle of manner. From the perspective of relevance theory, humor comes from the contrast of 
express-reasoning, maximum relevance principle and best relevance principle. In fact, there is much crosstalk that conveys humor through the combination of cooperative principle and relevance theory, sometimes it is not enough to explain humor alone with one principle, relevance theory is built on cooperative principle. Therefore, the author believes that both theories have their interpretation power and persuasion to the generation of humor.

\section{REFERENCES}

[1] Daren Tan. (1997). Humor and Speech Humor. Beijing: Beijing.Life $\cdot$ Reading, Xinzhi Sanlian Bookstore.

[2] Fei Wang. (2017). See the Humorous Words in Crosstalk "I Want to Attend the Spring Festival Gala" From the Perspective of Relevance Theory. Journal of Hubei Open Vocational College, 3,151-153.

[3] Feng Xie, Shuyun Zheng. (2007). Humour and the Discourse Analysis of Chinese Crosstalk. Journal of Shanxi Agricultural University (Social Sciences Edition), 4,417-420.

[4] Jinbang Du,Weihe Zhong. (2013). Discourse Analysis. Wuhan: Wuhan Publishing House.

[5] Liya Song, Xiaomin Yao. (2019). Interpretation of English Jokes and Speech Humor From the Perspective of Relevance theory. Journal of Heilongjiang Institute of Education, 5, 127-129.

[6] Mengjing Liu. (2020). Study on Verbal Humor in Crosstalk Art .Central China Normal University.

[7] Ning Wang. (2013). Crosstalk Speech Humor From the Perspective of Cooperation Principles and Relevance Theory. Hebei University.

[8] Qing Yang. (2011). Analysis of Word Humor in the Movie "The King's Speech". Film literature, 19, 147-148.

[9] Shiyan Zhang. (2021). The Overall Relevance in the Classroom-Based on Lesson Analysis. Basic Education Course, 5, 43-50.

[10] Sperber \& Wilson. (2001). Relevance: Communication and Cognition. Oxford: Blackwell.

[11] Xue Liang. (2012). Study the Verbal Humor in English Jokes From the Perspective of Relevance Theory. Liaoning University.

[12] Zheshi Mao. (2005). The Relevance of the Crosstalk Language. Rhetoric Learning, 6, 75-77.

Xia Li was born in Chongqing, China in 1998. She received her bachelor of arts degree from Chongqing Institute of Foreign Studies in 2020.

Now she is a graduate student in Chongqing Normal University, majoring in English education, her research interests mainly focused on English education. She published some papers such as Visual Analysis of Core Literacy Based on CiteSpace in IEEE conference. 